\title{
Hepatotoxicidade associada ao uso de esteroides anabolizantes
}

\author{
Hepatotoxicity induced by anabolic steroids
}

\author{
Mónica Brinquinho ${ }^{1}$, Ana Andresa Sousa ${ }^{1}$, Janine Resende ${ }^{2}$, João Valente ${ }^{3}$ \\ ${ }^{1}$ Interna de Formação Específica de Medicina Interna. ${ }^{2}$ Assistente Hospitalar de Medicina Interna. ${ }^{3}$ Assistente Hospitalar Graduado de Medicina Interna \\ Serviço de Medicina Interna - Unidade de Cuidados Intermédios de Medicina, Centro Hospitalar Vila Nova Gaia/Espinho
}

\begin{abstract}
Resumo
0 consumo de esteroides androgénicos anabolizantes tem vindo a aumentar no meio desportivo amador, sendo de fácil acesso apesar de se tratarem de substâncias proibidas. Estão descritos múltiplos efeitos laterais, sendo a hepatotoxicidade uma das mais reportadas. Apresentam-se dois casos clínicos representativos da lesão hepática associada ao consumo de esteroides anabolizantes. Ambos evidenciaram morbilidade significativa, embora nenhum deles tenha evoluído para falência hepática. Os autores pretendem chamar a atenção para o consumo destes fármacos, particularmente frequente em indivíduos jovens, praticantes de desporto amador.

Palabras clave: Anabolizantes, Andrógenos, hepatitis tóxica
\end{abstract}

\section{Introdução}

Os esteroides androgénicos anabolizantes (EAA) são derivados sintéticos da testosterona ${ }^{1}$, e têm efeitos androgénicos e anabólicos indissociáveis. ${ }^{2}$

A sua utilização no meio desportivo profissional está descrita há várias décadas, estando estas substâncias na Lista de Substâncias Proibidas do Comité Olímpico Internacional desde $1975^{3}$. No entanto, nos últimos anos tem-se assistido a um aumento do consumo mesmo em meio amador, visando a melhoria estética e aumento rápido da massa muscular. A prevalência exata do consumo é difícil de estimar, dada a sua ilegalidade. Em Portugal, das amostras recolhidas pela Autoridade Antidopagem, 10\% foram positivas para EAA em 2014; ; ao passo que 0 estudo de Massada M. et a ${ }^{5}$, referia que $63,6 \%$ dos praticantes de musculação dos ginásios do grande Porto já tinham utilizado EAA.

0 padrão típico de utilização dos EAA consiste na combinação de vários esteroides, com vista à maximização dos efeitos anabólicos e diminuição de feitos androgénicos. São habitualmente consumidos em ciclos de 6 a 12 semanas, alternados com períodos livres de EAA de 4 a 6 semanas e as doses utilizadas ultrapassam largamente as prescritas como terapêutica de substituição. São ainda utilizados fármacos acessórios com vista à minimização de efeitos laterais. ${ }^{2,5,6}$

Os efeitos laterais associados ao consumo de EAA afetam vários sistemas - cardiovascular, endócrino, hepático, musculosquelético e psiquiátrico. Do ponto de vista hepático

\begin{abstract}
Anabolic androgenic steroid use has grown, particularly in amateur sports and, although they are illegal substances, sportsmen have easy access to them. Many side effects are associated with consumption of these substances; hepatotoxicity is one of the most reported. The authors describe 2 patients with hepatotoxicity related to consumption of anabolic androgenic steroid use. Both showed considerable morbidity, but none developed fulminant hepatic failure. The authors aim to draw attention to anabolic steroid use, particularly among young amateur sportsmen.

Keywords: Anabolic agents, Androgenic agents, Drug-induced hepatotoxicity
\end{abstract}

estão descritos vários efeitos nomeadamente: colestase intrahepática, hepatite, adenoma e carcinoma hepatocelular. Os efeitos hepatotóxicos são mais frequentes com agentes $17 \alpha$ alquilados como 0 estanozolol. 5,6,7

Os autores descrevem dois casos clínicos representativos da hepatotoxicidade associada ao consumo de EAA.

\section{CASO 1}

Homem de 24 anos, caucasiano. Barman, culturista. Sem antecedentes pessoais ou familiares relevantes. Sem hábitos farmacológicos. Sem hábitos tabágicos ou etílicos.

Refere quadro de astenia, colúria/ acolia, obstipação e icterícia conjuntival com cerca de 15 dias de evolução. Referência a labilidade emocional e humor depressivo. Por agravamento dos sintomas (com icterícia da pele) e aparecimento de prurido recorre ao SU. Quando questionado referência a consumo de Winstro|ß (estanozolol), em ciclo de 8 semanas de dose crescente (mas desconhecida), tendo terminado 2 semanas previamente à admissão. Referência também a consumo de suplementos proteicos e vitamínicos. Negou consumo de outras drogas ilícitas ou chás, sem história de transfusões sanguíneas. Negou viagens recentes, consumo de água não potável e comportamentos sexuais de risco. À admissão apresentava-se consciente, colaborante e orientado, com icterícia das escleróticas e da pele. Eupneico, normotenso e normocárdico, apirético. Abdómen sem deformidades ou circulação colateral, mole e depressível, doloroso à palpação do hipocôndrio direito mas sem defesa ou sinais de irritação peritoneal; fígado palpável cerca de $5 \mathrm{~cm}$ abaixo da grade costal, doloroso mas sem nodularidades. Sem edemas. Sem outras alterações ao exame objetivo.

Foi efetuado estudo analítico que revelou elevação das transa- 
Tabela1. Estudo analítico (caso 1)

\begin{tabular}{|l|c|c|c|c|c|c|c|}
\hline & Referência & D1 & D5 & D10 & D15 & D20 & D60 \\
\hline Hemoglobina (g/dL) & $13-18$ & 14,9 & 13,6 & 14 & 14,1 & 14 & 15,3 \\
\hline Leucócitos (x103//L) & $3,8-10,6$ & 9,87 & 5,86 & 13,9 & 13,09 & 15,3 & 6,92 \\
\hline Plaquetas (x103/uL) & $150-440$ & 272 & 289 & 348 & 420 & 412 & 183 \\
\hline Creatinina (mg/dL) & $0,67-1,17$ & 0,7 & 1,3 & 1,37 & 1,48 & 1,15 & 1,09 \\
\hline Ureia (mg/dL) & $13-43$ & 30 & 31 & 26 & 36 & 43 & 35 \\
\hline $\begin{array}{l}\text { lonograma (Na+, } \mathrm{K}^{+} \\
\text {e Cl) }\end{array}$ & & $\mathrm{N}$ & $\mathrm{N}$ & $\mathrm{N}$ & $\mathrm{N}$ & $\mathrm{N}$ & $\mathrm{N}$ \\
\hline TG0 (U/L) & $4-33$ & 59 & 58 & 54 & 57 & 29 & 25 \\
\hline TGP (U/L) & $4-50$ & 89 & 73 & 53 & 60 & 71 & 41 \\
\hline GGT (U/L) & $5-61$ & 67 & 72 & 68 & 72 & 59 & 56 \\
\hline FA (U/L) & $40-129$ & 156 & 125 & 214 & 226 & 166 & 102 \\
\hline $\begin{array}{l}\text { Bilirrubina Total (mg/ } \\
\text { dL) }\end{array}$ & $0,1-1,1$ & 31,6 & 33,94 & 47,4 & 52,12 & 37,67 & 1,59 \\
\hline $\begin{array}{l}\text { Bilirrubina direta } \\
\text { (mg/dL) }\end{array}$ & $0,1-0,3$ & 25,42 & 33 & 44,7 & 48,83 & 31,54 & 0,96 \\
\hline Albumina (g/dL) & $3,4-4,8$ & 4,4 & 4,2 & 4 & 4,6 & 4 & 4,8 \\
\hline $\begin{array}{l}\text { Proteínas totais } \\
\text { (g/dL) }\end{array}$ & $6,4-8,3$ & 6,2 & 6,3 & 6,1 & 6,6 & 6,2 & 7,3 \\
\hline DHL (U/L) & $135-225$ & 313 & - & 240 & - & - & 215 \\
\hline INR /TP & $-/>70$ & $1,05 / 93 \%$ & $=$ & $=$ & $=$ & $=$ & \\
\hline
\end{tabular}

Tabela 2. Estudo analítico (caso 2)

\begin{tabular}{|c|c|c|c|c|c|c|c|c|}
\hline & Referência & D1 & D3 & D7 & D15 & D25 & D60 & D120 \\
\hline $\begin{array}{l}\text { Hemoglobina } \\
(\mathrm{g} / \mathrm{dL})\end{array}$ & $13-18$ & 14,6 & 15 & 14,8 & 14,4 & 15.3 & 14,7 & 15,2 \\
\hline $\begin{array}{l}\text { Leucócitos } \\
\text { (x103/uL) }\end{array}$ & $3,8-10,6$ & 15,7 & 13 & 13,71 & 17,67 & 22,19 & 9,63 & 9,69 \\
\hline $\begin{array}{l}\text { Plaquetas (x103/ } \\
\mathrm{uL})\end{array}$ & $150-440$ & 485 & 469 & 418 & 395 & 384 & 294 & 294 \\
\hline $\begin{array}{l}\text { Creatinina (mg/ } \\
\mathrm{dL})\end{array}$ & $0,67-1,17$ & 1,19 & 1,31 & 1,26 & 1,17 & 1,04 & 1,08 & 1,01 \\
\hline Ureia (mg/dL) & $13-43$ & 33 & 37 & 34 & 27 & 36 & 33 & 34 \\
\hline lonograma & & N & $\mathrm{N}$ & N & N & N & N & N \\
\hline TGO (U/L) & $4-33$ & - & 66 & 52 & 48 & 62 & 93 & 38 \\
\hline TGP (U/L) & $4-50$ & 78 & 79 & 79 & 72 & 133 & 162 & 66 \\
\hline GGT (U/L) & $5-61$ & - & 86 & 68 & 68 & 83 & 144 & 54 \\
\hline $\mathrm{FA}(\mathrm{U} / \mathrm{L})$ & $40-129$ & - & 359 & 386 & 387 & 387 & 271 & 113 \\
\hline $\begin{array}{l}\text { Bilirrubina total } \\
\text { (mg/dL) }\end{array}$ & $0,1-1,1$ & 11,42 & 13,46 & 18,32 & 21,41 & 18,69 & 4,57 & 0,77 \\
\hline $\begin{array}{l}\text { Bilirrubina direta } \\
\text { (mg/dL) }\end{array}$ & $0,1-0,3$ & 10,31 & 12,38 & 16,6 & 18,8 & 16,84 & 3,71 & - \\
\hline Albumina (g/dL) & $3,4-4,8$ & 4,2 & 4,2 & 3,7 & 4 & 3,7 & 4,2 & 4,7 \\
\hline $\begin{array}{l}\text { Proteínas totais } \\
(\mathrm{g} / \mathrm{dL})\end{array}$ & $6,4-8,3$ & - & 6,6 & 6,7 & - & - & 7,2 & 6,8 \\
\hline DHL (U/L) & $135-225$ & 189 & 234 & 216 & 204 & - & 171 & 146 \\
\hline INR /TP & $-1>70$ & 0,92;/116\% & $=$ & $=$ & $=$ & $=$ & $=$ & $=$ \\
\hline
\end{tabular}

minases (aminotransferase aspartato (TGO) e aminotransferase alanina (TGP)> 1,8xlimite superior da normalidade (LSN)) com aumento das enzimas de colestase (gama-glutamiltransferase (GGT) > $1,1 \times L S N$ e fosfatase alcalina (FA) $>1,2 \times L S N$ ), e hiperbilirrubinemia à custa da bilirrubina direta (ver Tabela 1). Do estudo efetuado salienta-se ainda INR e tempo de protrombina normais, marcadores víricos (incluindo vírus da hepatite $\mathrm{A}, \mathrm{B}$ e C e VIH) negativos, imunologia (anticorpos antinucleares, anti-mitocôndria, anti-músculo liso, anticorpos LKM-1 e anti-antigénios hepáticos) negativa, ceruloplasmina negativa e serologias (parvovírus B19, citomegalovirus e Epstein-Barr) negativas. 0 estudo da cinética do ferro não demonstrou alterações.

Foi efetuada ecografia abdominal - "fígado de dimensões aumentadas $(18 \mathrm{~cm})$, contornos regulares e ecoestrutura sem alterações aparentes. Veia porta e suprahepáticas permeáveis. Vias biliares intra e extrahepáticas de normal calibre. Vesícula biliar de paredes regulares e finas, sem imagens endoluminais sugestivas de litíase. Pâncreas com dimensões e morfologia normais, sem alterações valorizáveis da ecoestrutura. Esplenomegalia homogénea com $14,6 \mathrm{~cm}$ de maior eixo. Retroperitoneu superior sem alterações aparentes. Sem ascite".

Foi efetuada biópsia hepática para esclarecimento etiológico: "alargamento dos espaços porta por fibrose, moderado infiltrado inflamatório de linfócitos e neutrófilos, hepatite de interface e lobular, focal sem necrose; colestase intracanicular perivenular-compatível com hepatite tóxica."

Iniciou fluidoterapia, ácido ursodesoxicólico e prednisolona 60mg p.os com desmame posterior.

Registou-se evolução favorável ao longo do internamento, com melhoria do prurido e sem aparecimento de insuficiência hepática. Teve alta orientado para a consulta de Medicina Interna, onde manteve seguimento, com indicação de suspensão de consumo de EAA.

\section{Caso 2}

Homem de 52 anos, caucasiano. Chefe de segurança; frequenta ginásio. Sem antecedentes pessoais ou familiares relevantes. Sem hábitos farmacológicos. Sem hábitos tabágicos. Hábitos etilicos ligeiros.

Recorre ao serviço de urgência por história de colúria, acolia, prurido ligeiro e icterícia das escleróticas com cerca de 8 dias de evolução. Sem outra sintomatologia associada. Referência a toma de EAA desde há 3 meses - testosterona, trembolona e nandrolona injetáveis, em dias alternados (dose desconhecida).

À admissão apirético, normotenso e normocárdico. Escleróticas ictéricas, abdómen depressível, indolor à palpação com bordo inferior do fígado palpável $3 \mathrm{~cm}$ abaixo da grade costal sem nodularidades. Sem outras alterações ao exame objetivo. 
Efetuado estudo analítico - ver Tabela 2. De salientar elevação das transaminases (TGP $>1,5 \times L S N$ ) e da gamaglutamiltransferase $(>1,4 \times \mathrm{LSN})$, hiperbilirrubinemia à custa da direta (bilirrubina total $11,42 \mathrm{mg} / \mathrm{dL}$ com bilirrubina direta 10,3 mg/dL); INR e taxa de protrombina normais, albumina normal e marcadores víricos (vírus da hepatite $A, B, C$ e VIH) negativos. Efetuado estudo imunológico (ANA, anti-mitocôndria, anti-músculo liso, anticorpos LKM-1 e anti-antigénios hepáticos) negativo, doseamento de ceruloplasmina, alfa1-antitripsina e cinética do ferro normais.

A ecografia abdominal demonstrou: fígado de dimensões aumentadas (17,6 cm na linha médioclavicular), contornos lobulados e ecostrutura sem alterações aparentes. Sem lesões focais. Baço de dimensões normais. Sem alterações das vias biliares, vesícula biliar, pâncreas e retroperitoneu; sem ascite.

Foi orientado para consulta externa para seguimento com indicação de repouso, hidratação oral e suspensão de consumo de EAA e álcool.

\section{Discussão}

Os casos descritos estão em concordância com a literatura que descreve maior utilização de EAA por adultos do sexo masculino, com boa condição física, sem antecedentes patológicos e com o objetivo de aumentar a massa e força muscular. ${ }^{3,7}$ Ambos adquiriram os EAA no ginásio habitual, demonstrando o fácil acesso a estes fármacos, apesar de serem substâncias proibidas.

0 primeiro caso reflete a utilização de um agente $17 \alpha$ alquilado, o estanozolol em associação com complexos proteicos e vitamínicos. 0 doente apresentou prurido severo, que respondeu à utilização de ácido ursodesoxicólico com evidência de colestase franca no estudo analítico. 0 pico de bilirrubina total (BT) foi de $52 \mathrm{mg} / \mathrm{dL}$ (>47xLSN), tendo ocorrido cerca de 4 semanas após o início da sintomatologia. Registou-se posteriormente descida progressiva destes valores, estando praticamente normalizados 2 meses após início do quadro.

Estes dados estão de acordo com o descrito por Robles-Diaz e colaboradores ${ }^{7}$ - a colestase associada ao uso de EAA pode ser severa, motivando a admissão hospitalar mas normalmente não cursa com insuficiência hepática fulminante. 0 segundo caso demonstra lesão hepática associada à uti- lização de vários EAA. Comparativamente, neste caso o pico de BT atingido foi inferior ao do primeiro caso (>19xLSN), tendo, por outro lado, ocorrido elevação mais acentuada das transaminases, e com prolongamento do quadro ao longo de vários meses.

Estas diferenças podem dever-se por um lado à combinação de vários agentes não alquilados, que ocasionam lesão hepática mista, ou, por outro lado, ao consumo concomitante de álcool. De facto, Shahidi NT descreve maior hepatotoxicidade dos EAA quando associados a doença hepática pré-existente ou uso concomitante de outros fármacos ou substâncias hepatotóxicas. ${ }^{8}$

Em ambos, outras causas de lesão hepática foram excluídas. Apesar da morbilidade associada ao seu consumo, com necessidade de internamento no primeiro doente e de seguimento apertado, ao longo de vários meses no segundo, houve resolução do quadro com a suspensão dos EAA, sem evolução para insuficiência hepática ou para doença hepática crónica (nenhum dos doentes se encontra em seguimento em consulta externa atualmente).

Com a apresentação destes casos, os autores pretendem chamar a atenção para o consumo de EAA, em particular em grupos de atletas não profissionais onde o controlo por parte das autoridades competentes não é tão apertado.

\section{Bibliografia}

1. Ferreira, U.M.G, Ferreira, A.C.D., Azevedo A.M.P, Medeiros, R.L., Silva, C.A.B. Esteroides androgénicos. RBPS. 2007, 20 (4): 267-275.

2. Joseph, J.F. Parr, M.K. Synthetic androgens as designer supplements. Current Neuropharmacology. 2015, 13: 89-100.

3. Kafrouni MI, Anders RA, Verma S. Hepatotoxicity associated with dietary supplements containing anabolic steroids. Clin Gastrenterol Hepatol 2007, 5: 809-812.

4. Instituto Português do Desporto e Juventude: http://www.adop.pt/media/8930/ ADoP\%202014\%20Dados\%20Estatísticos\%20(site).pdf

5. Massada, M., Ribeiro, S., Ferreira, V. Consumo de substâncias dopantes no desporto recreativo português - um estudo em praticantes de musculação. Ver Med Dep Informa, 2011, 2(4)19-21.

6. Ribeiro, B. Esteroides androgénicos anabolizantes - uma breve revisão. Ver Med Dep Informa, 2011, 2(5)22-25.

7. Robles-Diaz, M., Gonzalez-Jimenez, A., Medina-Caliz, C., et al. Distinct phenotype of hepatotoxicity associated with illicit use of anabolic steroids. Aliment Pharmacol Ther 2015; 41:116-125

8. Shahidi NT. A review of the chemistry, biological action, and clinical applications of anabolic-androgenic steroids. Clin Ther 2001;23:1355-1390. 